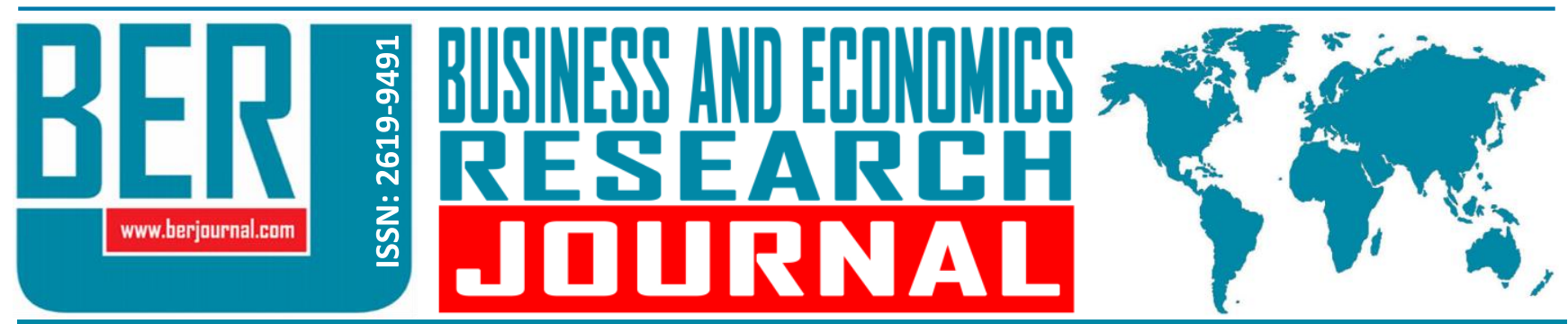

Business and Economics Research Journal Vol. 10, No. 1, 2019, pp. 41-53 doi: 10.20409/berj.2019.155

\section{Geçiş Ekonomilerinde Doğrudan Yabancı Yatırımların Ekonomik Büyüme Üzerine Etkisi: Dinamik Panel Veri Analizi*}

\section{Mustafa Ozcag $^{\mathrm{a}}$, E. Yasemin Bozdaglioglu ${ }^{\mathrm{b}}$, Hatice Kucukkaya ${ }^{\mathrm{c}}$}

Öz: Geçiş ekonomilerinin ekonomik büyüme trendleri incelendiğinde, geçiş süreci ile birlikte söz konusu ülkelerin ekonomik büyüme performanslarında olumlu gelişmelerin ortaya çıktığı görülebilmektedir. Bu çalışmada, 1997-2016 dönemi için 27 geçiş ekonomisine giriş yapan doğrudan yabancı yatırımların ekonomik büyüme oranlarına olan etkisi Neoklasik ve içsel büyüme teorileri çerçevesinde modellenmektedir. Neoklasik ve içsel Büyüme Teorileri çerçevesinde bu etkinin araştırılabilmesi için beşeri sermaye faktörü de önemli rol oynamaktadır. Çalışmada, incelenen dönem için doğrudan yabancı yatırımlar ve ekonomik büyüme arasındaki ilişki, güncel dinamik panel tahmincilerinden olan Arellano-Bond, Arellano-Bondmax ve Arellano-Bond 2 aşamalı GMM (Genelleştirilmiş Momentler Metodu) tahmincileri ile test edilmektedir. Modelde tahmin edilen ekonomik büyüme oranları, beşeri sermaye ve ticaret hacmi değişkenlerinin değerlerinin istatistiksel olarak anlamlı ve katsayılarının pozitif olduğu sonucuna ulaşılmaktadır. Çalışmanın en dikkat çekici noktası ise; doğrudan yabancı yatırımların beşeri sermaye artışı ile desteklenmesi durumunda ekonomik büyüme üzerinde çok daha fazla etki yaratabileceği sonucudur.

\section{The Impact of Foreign Direct Investments on Economic Growth in Transition Economies: Dynamic Panel Data Analysis}

Abstract: In the transition economies, together with the transition process, positive developments in economic growth performances can be seen. In this study, the impact of foreign direct investment on the economic growth rates of 27 transition economies for the period 19972016 is modeled within the theories of neoclassical and endogenous growth. In order to investigate this effect in the framework of Neoclassical and endogenous growth theories, the human capital factor also plays an important role. For this reason, the relationship between foreign direct investment and economic growth for the specified period is tested with the estimators Arellano-Bond, Arellano-Bondmax and Arellano-Bond 2 Stage GMM (Generalized Method of Moments) which are current dynamic panel model estimators. Economic growth, human capital and trade volume variables are statistically significant and the coefficients are positive. The most striking result of working is; if foreign direct investment is supported by human capital growth, it will have much more impact on economic growth.
Anahtar Sözcükler:

Ekonomik Büyüme, Geçiş Ekonomileri, Doğrudan Yabancı Yatırımlar, Dinamik Panel Veri Analizi

JEL: C23, F21, O47, P20

Geliş

Düzeltme : 18 Eylül 2018

Kabul : 26 Aralık 2018

Tür : : Araştırma

Keywords: Economic Growth Transition Economies, Foreign Direct Investment, Dynamic Panel Data Analysis

JEL: C23, F21, O47, P20

Received : 09 August 2018

Revised : 18 September 2018

Accepted : 26 December 2018

Type : Research

Cite this article as: Ozcag, M., Bozdaglioglu, E. Y., \& Kucukkaya, H. (2019). Geçiş ekonomilerinde doğrudan yabancı yatırımların ekonomik büyüme üzerine etkisi: Dinamik panel veri analizi. Business and Economics Research Journal, 10(1), 41-53.

The current issue and archive of this Journal is available at: www.berjournal.com

Assoc. Prof., PhD., Aydin Adnan Menderes University, Department of Economics, Aydin, Turkiye, mozcag@adu.edu.tr (ORCID ID: 0000-0001-5473-8148)

b Asst. Prof., PhD., Aydin Adnan Menderes University, Department of Economics, Aydin, Turkiye, yuyar@adu.edu.tr (ORCID ID: 0000-0002-9409-8509)

Asst. Prof., PhD., Aydin Adnan Menderes University, Department of Economics, Aydin, Turkiye, hatice.kucukkaya @adu.edu.tr (ORCID ID: 0000-0002-9938-9794) 


\section{Giriş}

Ülkelerin uzun dönem büyüme süreçleri birçok belirleyici tarafından şekillenmektedir. Sermaye birikimi, demografik faktörler, teknolojik gelişme, doğal kaynaklar, sosyal ve kültürel faktörler gibi çeşitli unsurlar, ekonomik büyüme süreçlerini her ülke için farklı boyutlarda ve formlarda etkilemektedir. Tasarruf birikimi ve sermaye artışı gibi hususlar ise ekonomik büyümeyi belirleyen temel makroekonomik değişkenler arasında yer almaktadır. Düşük gelir düzeyinden kaynaklanan tasarruf yetersizliği, yatırımlar için gerekli olan sermaye birikiminin de büyüme sürecinde itici bir güç olmasına engel olmaktadır.

Teknolojik gelişmelerin hızlanmasıyla daha büyük ivme kazanan uluslararası sermaye hareketliliğinin varlığının, tasarrufların yetersiz olduğu ekonomilerde sermaye eksikliğinde yaşanan açıkların giderilmesinde etkin rol oynadığı söylenebilir. Uluslararası sermaye hareketleri; portföy yatırımları ve doğrudan yatırımlar şeklinde ortaya çıkabilmektedir. Belli bir risk üstlenerek bir başka ülkeden tahvil, hisse senedi ya da borç senedi gibi finansal varlıkların satın alınması şeklinde oluşan portföy yatırımları herhangi bir risk ya da istikrarsızlık gördükleri durumda giriş yaptıkları ülkeyi terk edebilmektedir. Doğrudan yabancı yatırımlar ise, herhangi bir firmayı satın almak, kuruluş aşamasında olan bir firma için sermaye teminini sağlamak ya da var olan bir şirketin sermayesini yükseltmek kanalıyla başka bir ülkedeki firmalara yapılan ve beraberinde bilgi birikimi ve teknolojiyi de getiren yatırımlardır (Alagöz, Erdoğan ve Topallı, 2008: 83). Daha düşük maliyetlerle çalışabilmek için üretim faktör fiyatlarının nispeten daha ucuz olduğu, iç talebin ve altyapının yeterli bulunduğu ülkeleri daha çok tercih etmekte olan doğrudan yabancı yatırımlar, gittikleri ülkelerde istihdam, döviz, know-how gibi çeşitli alanlarda büyük avantajlar sağlamaktadır.

1950'li yıllardan itibaren dünya üzerinde doğrudan yabancı yatırımlarda yaşanan olumlu gelişmeler, bu alandaki teorik altyapının da hazırlanmasına zemin hazırlamıştır. Sürecin başlangııında sadece gelişmiş ülke ekonomilerinde büyük ivme kazanan doğrudan yabancı yatırımlar, 1970'li yıllarla birlikte gelişmekte olan ülkeler için de büyük fırsatlar yaratmıştır (Yapraklı, 2006: 26). Özellikle II. Dünya Savaşı ile Doğu Bloku’nun sona erdiği 1989 yılına kadar geçen süre zarfında, gelişmiş ülkelerin tamamında doğrudan yabancı yatırımları çekebilmek için büyük çabalar harcanmıştır. Doğrudan yabancı sermaye yatırımlarına daha fazla ihtiyaç duyan gelişmekte olan ülkelerde ise, ilgili dönemde doğrudan yabansı sermaye yatırımlarına bazı endişelerle şüphe ile yaklaşılmış ve önemli bir finansman kaynağından mahrum kalmışlardır. Illerleyen süreçle birlikte gelişmekte olan ülkelerin doğrudan yabancı sermayeye olan bu olumsuz bakış açısı da değişime uğramış, sömürgecilik faaliyetlerinin bir aracı olduğu düşüncesinden uzaklaşılmıştır (Tandırcıoğlu ve Özen, 2003: 107).

Doğrudan yabancı sermaye yatırımları konusunun teorik içeriği 1960'lı yıllara kadar Neo-Klasik sermaye hareketleri teorisi çerçevesinde açıklanmıştır. Bu yaklaşıma göre sermaye, düşük getiriye sahip bölgelerden yüksek getirili bölgelere doğru yer değiştirmektedir. Bu teoride, portföy yatırımlarını temel belirleyicisi olan faiz oranlarındaki farklııkların doğrudan yabancı sermaye yatırımlarını da etkilediği görüşü kabul edilmiştir. Marksist teori de benzer şekilde kar oranları üzerinde odaklanmıştır. Teoriye göre kapitalist ekonomilerde kar oranlarının azalma yönünde seyrediyor olması, sermayenin daha fazla getiri sağlayacağı alanlara kaymasına neden olacaktır (Şişman ve Öztürk, 2010: 54).

Farklı Getiri Oranları Hipotezi, doğrudan yabancı sermaye yatırımlarını açıklamaya yönelik oluşturulan ilk düşüncelerden bir tanesidir. Bu hipoteze göre; sermaye, oransal olarak düşük getiri sağladığı ekonomilerden daha yüksek getiriye sahip ekonomilere doğru hareket etmektedir. Temelleri Tobin ve Markowitz tarafından 1950'lerde oluşturulan Portföy Çeşitliliği Kuramı, doğrudan yatırım kararlarında getiri oranı ile birlikte yatırım riskini de barındırmaktadır. Piyasa Büyüklüğü Hipotezi ise; ülkeye giriş yapan doğrudan yabancı sermaye yatırım miktarını ilgili ülkenin sahip olduğu pazar büyüklüğü ile ilişkilendirmektedir. Doğrudan yabancı sermaye yatırımlarını açıklamada kullanılan teorilerden bir diğeri Oligapolistik Tepki Teorisi'dir. Teori'ye göre, oligopol bir endüstride faaliyet gösteren firmaların aynı endüstrideki bir diğer şirketin önemli bir yabancı piyasada üretime başlaması halinde diğer şirketlerin de o firmayı takip edeceği üzerine şekillenmektedir (Şişman ve Öztürk, 2010:53). Eksik rekabet koşulları altında oluşturulan bir diğer teori olan iç̧selleştirme Teorisi, işletme fonksiyonlarının hiyerarşik entegrasyonunu gösteren içsel organizasyon ile doğrudan yabancı sermaye yatırımları arasında bir ilişki kurmaktadır. Bu teori, firmaların sahip oldukları özelliklerini lisanslama vasıtasıyla satmak yerine doğrudan yabancı sermaye 
yatırımlarına yönelerek satışın yapılacağı ülke piyasalarında risklerden kaçınabileceklerini belirtmektedir (Hansen, 1998: 33). Doğrudan yabancı sermaye yatırımlarını açıklamaya yönelik oluşturulan bir diğer hipotez Yerel Avantajlar Hipotezi'dir. Hipotez, işgücü ve doğal kaynaklar gibi hareketliliği sınırlı olan kaynaklardan yararlanabilmek adına söz konusu ülkeye doğrudan yatııılarını yönlendirmeleri çerçevesinde temellenmektedir. Genel denge modeli üzerine şekillenen yeni doğrudan yabancı yatırım teorileri ise, artan ölçek getirileri, eksik rekabet ve çok uluslu şirketlerin kendilerine özgü avantajlar öncelikli olarak insan sermayesi, ticari marka ve patentler gibi maddi olmayan varlıklardan oluşan bilgi sermayesi üzerine kurgulanmaktadır (Jadhav, 2012: 6).

Doğrudan yabancı yatırımlar, giriş yaptıkları ülkede çeşitli etkiler yaratmaktadır. Sadece yatırım ve sermaye stoğunu arttırmakla kalmayıp, aynı zamanda yeni üretim kapasitesi yaratarak istihdam artışına da olumlu katkılar yapar. Bununla birlikte, teknoloji ve yönetsel beceriler gibi maddi olmayan varlıkları da ev sahibi ülkeye transfer etmek gibi önemli bir avantaj da sağlamaktadır. Diğer taraftan, bir ülkenin doğrudan yabancı yatıımların kazandıracağı bu avantajlardan yeterince faydalanabilmesi için bazı ekonomik ve kurumsal yeterliliklere de sahip olması gerekmektedir. UNCTAD'ın 1998 yılında yayınladığı raporda bu yeterlilikler; siyasi ve ekonomik istikrar, düşük vergi yükleri, ekonomik entegrasyonlara üyelik, özelleştirme faaliyetlerinin büyüklüğü, daha az bürokratik işlemler, yatırım teşvikleri, yatııım sonrası hizmetlerin yeterliliği, piyasanın yeterince geniş olması, fiziki altyapının yeterli olması, işgücünün verimli olması, fiyat ve döviz kuru düzeylerinin fazla oynak olmaması, dışa açıklık seviyesinin yüksek olması gibi başlıklar altında toplanmıştır (UNCTAD, 1998: 91).

Sosyalist ekonomik sistem ile yönetilirken daha sonra piyasa ekonomisinin benimsendiği ülkeler geçiş ekonomileri olarak adlandırılmaktadır. Bu ülkelerde geçiş sürecinde bir taraftan ekonomik sistemi uluslararası piyasalarla entegre edebilmek, serbestleşme ve özelleştirme faaliyetleri gerçekleştirilirken, diğer taraftan tüm bu süreci kontrol edebilmek için yoğun şekilde devlet müdahalesi de gerekli olmuştur (Yavuz, 2006: 89). Liberalizasyon, makro ekonomik istikrar, yeniden yapılanma ve özelleştirme ile yasal ve kurumsal reformların gerçekleştirilmesi IMF tarafından geçiş sürecinin ana bileşenleri olarak gösterilmektedir (IMF, 2000a). Geçiş sürecini yaşayan hemen hemen tüm ülkelerde birçok ekonomik ve sosyal sorunların da ortaya çıktığı görülmüştür. Üretim miktarında yaşanan azalmalara bağlı olarak yaşanan yüksek işsizlik oranları, liberalleşme ile birlikte yüksek rekabetin yerli firmalar üzerinde yarattığı olumsuzluklar, yurtiçi tasarruf oranındaki yetersizlikler geçiş ekonomisi ülkelerinin ekonomik büyümeleri üzerinde de negatif etkiler yaratmıştır. Özellikle tasarruf yetersizlikleri ve düşük teknolojik düzey gibi etmenler yurtiçi üretimin ve istihdamın arttırılmasında önemli engeller oluşturmuştur. Bu süreçte doğrudan yabancı yatırımlar istenilen büyüme oranlarına ulaşmada itici bir güç olarak karşımıza çıkmaktadır.

Bu genel çerçevede çalışmanın amacı; 27 geçiş ekonomisinde doğrudan yabancı yatırımların bu ülkelerin ekonomik büyümeleri üzerinde etkilerinin olup olmadığını belirlemeye çalışmaktır. Bu amaca yönelik olarak, 1997-2016 yıllarını kapsayan dönem için Genelleştirilmiş Momentler Metodu kullanılarak söz konusu ilişkiler belirlenmeye çalışılmıştır.

Çalışma dört bölümden oluşmaktadır. Giriş bölümünü takip eden ikinci bölümde literatür taramasına yer verilmiştir. Üçüncü bölümde ekonometrik model analiz ve bulgulara yer verilirken, dördüncü bölümde çalışmadan elde edilen sonuçlar ortaya konmuştur.

\section{Literatür Taraması}

Literatürde, doğrudan yabancı yatırımların ekonomik büyüme üzerindeki etkilerinin incelendiği ve farklı sonuçların elde edildiği birçok çalışma bulunmaktadır. Mankiw, Romer ve Weil (1992) başta olmak üzere Borenzstein, Gregorio ve Lee (1998), De Mello (1997), Flexner (2000), Zhang (2001), Khawar (2005), Li ve Liu (2005) gibi çalışmalar doğrudan yabancı yatırımlar ile ekonomik büyüme arasında bir ilişki olduğunu ortaya koymuşlardır. Diğer taraftan Carkovic ve Levin (2002), Katerina, Papanastasiou ve Vamvakidis (2004), Athukorola (2003) ve Durham (2004) doğrudan yabancı yatırımlar ile ekonomik büyüme arasında herhangi bir ilişkinin bulunmadığı sonucuna ulaşmıştır. 
Melnyk, Kubatko ve Pysarenko'nun (2014) çalışmaları, doğrudan yabancı yatırımların ekonomik büyüme üzerine etkisini incelemektedir. Komünizm sonrası geçiş ekonomilerinin incelendiği ve 26 ülke için 1998-2010 yıllarını kapsayan çalışma sonucunda doğrudan yabancı yatııımların ev sahibi ülkenin ekonomik büyümesi üzerinde önemli derecede etkilediği sonucuna ulaşılmıştır. Hoang, Wiboonchutikula ve Tubtimtong (2010) Wietnam'daki 31 eyalet ekonomisi üzerine yaptıkları çalışmada, 1995-2006 döneminde, doğrudan yabancı yatırımlardan ekonomik büyümeye doğru güçlü bir nedensellik olduğu ifade edilmektedir. Ağayev (2010) 25 geçiş ekonomisi üzerinde doğrudan yabancı sermaye yatırımları ile ekonomik büyüme arasındaki ilişkileri incelemektedir. Çalışmada panel eşbütünleşme ve panel nedensellik testleri uygulanarak elde edilen sonuçlar, doğrudan yabancı sermaye yatırımları ile ekonomik büyümenin uzun dönemde birlikte hareket ettiklerini ortaya koymaktadır. İki değişken arasında iki yönlü nedenselliğin bulunduğunun belirtildiği çalışmada, kısa dönemde doğrudan yabancı yatırımlardan ekonomik büyümeye doğru güçlü bir ilişkinin varlığı da ortaya konmuştur. Nath (2009) 13 geçiş ekonomisi üzerine yapmış olduğu çalışmada elde edilen bulgular literatürdeki diğer çalışmalara göre farklılık göstermektedir. Geçiş ekonomilerinde genel olarak doğrudan yabancı yatırımların ekonomik büyüme üzerinde herhangi bir anlamlı etkisinin bulunmadığı belirtilirken, yurtiçi yatırımlar ve ticaretin doğrudan yabancı yatırımlar üzerindeki etkisi kontrol edildiğinde anlamlı etkilere ulaşıldığı ifade edilmiştir. Apergis, Lyroudi ve Vamvakidis (2008) 1991-2004 yılları arasında 27 geçiş ekonomisini kapsayan çalışmalarında panel data yöntemi kullanılarak doğrudan yabancı yatırımlar ile ekonomik büyüme arasındaki ilişkileri analiz etmişlerdir. Panel eşbütünleşme ve nedensellik test sonuçlarına göre, ele alınan ülkelerde doğrudan yabancı yatırımlar ile ekonomik büyüme arasında herhangi bir anlamlı ilişki bulunmamıştır. Ghatak ve Halıcıoğlu (2006), 1991-2001 yıllarını kapsayan dönem için 140 ülke üzerinde 2006 yılında hazırladıkları çalışmalarında, doğrudan yabancı sermaye yatırımları ile ekonomik büyüme arasında anlamlı ve pozitif bir ilişkinin bulunduğu sonucuna ulaşmışlardır. Sohinger'in (2005) Avrupa'daki geçiş ekonomileri üzerine hazırlamış olduğu çalışmada, önemli bir dış finansman kaynağı olan doğrudan yabancı yatırımların fiziki sermaye stoğunu arttırma yoluyla incelenen ülkelerin ekonomik büyüme süreçlerine önemli katkılar sağladığı ve rekabetçilik düzeylerini olumlu yönde etkilediği ifade edilmiştir. Bevan ve Estrin (2004) Avrupa'daki geçiş ekonomileri üzerine yaptıkları çalışmalarında, doğrudan yabancı yatırımların hem kaynak ülkenin hem de ev sahibi geçiş ekonomisi ülkenin gayri safi yurtiçi hasılası ile pozitif ilişkili olduğu belirtilmektedir. Tian, Li ve Lo (2004) Çin'de bulunan 30 eyalet üzerine hazırlamış oldukları çalışmada, 1985-2000 yıllarını kapsayan dönem için, yüksek doğrudan yabancı yatırımların teknolojilerin yenilenmesi ve yüksek ekonomik büyüme hızları için gerekli olduğunu ifade etmektedir. Çalışmada, daha az geliş̧miş geçiş ekonomilerinin doğrudan yabancı yatırımları cesaretlendirmeleri gerektiği de belirtilmiştir. Lee ve Tcha (2004), geçiş ekonomileri üzerine 2004 yılında hazırladıkları çalışmalarında, doğrudan yabancı yatırımların doğrudan yatırımlara göre büyümeye daha fazla katkı yaptığını ileri sürmektedirler. Hansen ve Rand'ın (2004) 31 ülkeyi kapsayan 2004 yılı çalışmaları, panel eşbütünleşme ve nedensellik analizleri kullanılarak doğrudan yabancı sermaye yatırımlarının gayri safi yurtiçi hasıla üzerindeki etkilerini incelemektedir. Çalışmanın sonuçlarına göre, değişkenler arasında iki yönlü nedenselliğin varlığı ortaya konmuş ve uzun dönemde doğrudan yabancı sermaye yatırımlarının büyümeyi olumlu etkilediği belirtilmiştir. Kumar ve Naradhan'ın (2002), panel veri analizi kullanılarak 107 ülke üzerinde gerçekleştirdikleri çalışması, doğrudan yabancı yatırımlar ile ekonomik büyüme arasında pozitif bir ilişkinin bulunduğunu ileri sürmektedir. Campos ve Kinoshita (2002), 25 geçiş ekonomisinde doğrudan yabancı sermaye yatırımları ile ekonomik büyüme arasındaki ilişkileri incelemişlerdir. Elde edilen bulgular, doğrudan yabancı yatırımların büyüme üzerinde güçlü pozitif etkilerinin olduğunu ortaya koymuştur. Nair-Reichert ve Weinhold'un 2000 yılında yayınlanan çalışmalarında, panel nedensellik testleri kullanılarak gelişmekte olan ülkelerde doğrudan yabancı sermaye yatırımları ile ekonomik büyüme arasındaki nedensellik ilişkisi incelenmiştir. Çalışmada elde edilen bulgular, dışa açıklığı daha fazla ekonomilerde doğrudan yabancı yatırımların büyüme üzerindeki etkisinin daha fazla olduğunu ortaya koymaktadır.

\section{Ekonometrik Model, Analiz ve Bulgular}

Çalışmanın amacı; 1997-2016 döneminde 27 geçiş ekonomisinde doğrudan yabancı yatırımların ekonomik büyüme üzerindeki etkisini incelemektir. Bu bağlamda, Neoklasik ve içsel büyümenin teorik modelleri ve Romer (1990), Mankiw, Romer ve Weil (1992) ve Borensztein, Gregorio ve Lee (1998) gibi bazı 
ampirik analiz modelleri çerçevesinde, doğrudan yabancı yatırımların seçilmiş geçiş ekonomilerindeki ekonomik büyüme üzerindeki etkisi araştırılmaktadır.

\subsection{Büyüme Modeli}

Ekonomik büyümeyi etkileyen faktörler olarak; işgücü, beşeri sermaye, kamu harcamaları, ticaret hacmi değişkenlerinin yanı sıra doğrudan yabancı yatırımların da eklendiği bir üretim fonksiyonu türetilmiştir. Çalışmada kullanılan genişletilmiş üretim fonksiyonu aşağıdaki gibidir:

$$
Y=A F^{\beta 1} G E^{\beta 2} T^{\beta 3} H^{\beta 4}
$$

Modelde Y; GSYiH'yi, F; doğrudan yabancı yatırımları, GE; kamu harcamalarını, T; ticaret hacmini, H ise beşeri sermayeyi temsilen insanı kalkınma endeksini göstermektedir. A değişkeni; ölçek verimlilik katsayısı olarak faktör girdilerinde, F, GE, T ve $\mathrm{H}$ artışında ölçülemeyen kontrol ve politika değişkenlerini yakalayan ve çoğunlukla alan çalışmalarında büyümenin belirleyicileri olarak modele dahil edilen genel bir etkinlik faktörüdür.

Literatürde yaygın olarak kullanılan ülkelerin sermaye stoğunun büyüme oranını temsilen kamu harcamalarının GSYiH'ye oranı kullanılmıştır. Ekonometrik olarak bu değişimler regresyon katsayısının tahmini değerini değiştirir. Ancak, sermaye stoku tahminlerinin normal olarak hesaplanması halinde, herhangi bir bilgi kaybı olduğu anlamına gelmemektedir. Ülkelerin sermaye stokları konusunda veri sıkıntısı bulunduğundan, çoğu zaman sermaye stokları konusunda temsili değişkenler kullanılmaktadır.

Ülkelerin ticaret hacmini temsilen ihracata dayalı büyüme hipotezini dikkate alan çok sayıda ampirik çalışmadan hareketle, ticaret hacmi üretim fonksiyonuna ek bir faktör girdisi olarak eklenmiştir.

Ülke (i) ve zamanın ( $t$ ) teorik çerçevede işlemesine izin vermek için, aşağıdaki panel veri denklemi, doğrudan yabancı yatırımların geçiş ekonomilerinde ekonomik büyüme üzerindeki etkisini ampirik olarak değerlendirmek amacıyla kullanılmaktadır:

$$
\text { growth }_{i t}=\beta_{0}+\beta_{1} f d i_{i t}+\beta_{2} \text { gov }_{i t}+\beta_{3} \operatorname{tra}_{i t}+\beta_{4} h d i_{i t}+\varepsilon_{i t}
$$

$\mathrm{i}=1,2, \ldots, 27$, geçiş ekonomilerindeki her bir ülkeyi ifade etmektedir ve $\mathrm{t}$ ise 1996'dan 2017'ye kadar olan yılları göstermektedir. $\beta_{i}$ zamana göre sabit varsayılan yatay kesit etkiyi, $\varepsilon_{i t}$ ise stokastik hata terimini göstermektedir. IMF'nin Geçiş Ekonomileri Sınıflandırması'na göre (IMF, 2000b), 31 geçiş ekonomisinden 4 ülke (Lao, Tacikistan, Türkmenistan ve Özbekistan) veri eksikliği nedeniyle analiz dışında bırakılmıştır.

Bağımlı değişkengrowth ${ }_{i t}$ i ülkesinin $\mathrm{t}$ zamanındaki GSYiH yıllık büyüme oranıdır. Bağımsız değişkenler, ekonomik büyümenin belirleyicileri ile ilgili çeşitli faktörler dikkate alınarak oluşturulmuştur. $f d i_{i t}$, DYY'nin DYY girişinin GSYiH'ya oranı, gov $v_{i t}$ kamu harcamalarının GSYiH'ye oranı, $t r a i t$ GSYiH içindeki toplam ticaretin (ihracat+ ithalat) payını, $h d i_{i t}$ ise insani kalkınma indeksini göstermektedir. Denklem 2; Stata 14.2 paket programı kullanılarak tahmin edilmiştir.

Çalışmada kullanılan geçiş ekonomileri ülkeleri; Arnavutluk, Azerbaycan, Bosna-Hersek, Bulgaristan, Beyaz Rusya, ÇEK Cumhuriyeti, Çin, Ermenistan, Estonya, Gürcistan, Hırvatistan, Kamboçya, Kazakistan, Kırgızistan, Letonya, Litvanya, Macaristan, Makedonya, Moğolistan, Moldova, Polonya, Romanya, Rusya, Slovak Cumhuriyeti, Slovenya, Ukrayna ve Vietnam'dır. Veri eksikliği sebebiyle Lao, Özbekistan, Tacikistan ve Türkmenistan analiz dışında bırakılmıştır.

Analize dahil edilen ülkelerin bir çoğunun geçiş ekonomisi listesine giriş yılı 1992 olması ve bazı ülkelerdeki veri eksikliği sebebi ile çalışmanın dönemi 1997 yılından başlatılmak zorunda kalınmıştır. 


\subsection{Metodoloji}

Panel verilere dayalı analiz yöntemleri arasında dinamik panel veri analizleri en çok kullanılan yöntemlerden biridir. Dinamik panel veri modelleri ile geçmiş dönemdeki bağımlı değişkenin cari dönemdeki bağımlı değişken üzerindeki etkisi ölçülmektedir. Dinamik panel veri modelleri, statik panel veri modellerinden farklı olarak içerisinde gecikmeli değişken veya değişkenler olan modellerdir (Tatoğlu, 2013: $65)$.

Dinamik panel veri analizlerinde ise en fazla tercih edileni Arellano ve Bond (1991) tarafından önerilen "Genelleştirilmiş Momentler Metodu" (GMM)'dur. Bu yöntem, hata terimleri otokorelasyonlu olduğunda kullanılan bir yöntemdir. Bunun yanında hem sabit varyans hem de değişen varyans olması durumunda da uygun bir yöntemdir. Bu yöntemde ilk önce, birinci fark modeli araç değişken matrisi kullanılarak dönüştürülmekte bu dönüştürülmüş model Genelleştirilmiş En Küçük Kareler Yöntemi ile tahmin edilmektedir. Bu nedenle Genelleştirilmiş Momentler Tahmincisi, İki Aşamalı Araç Değişkenler Tahmincisi olarak da bilinmektedir (Tatoğlu, 2013: 80). Fark GMM olarak da adlandırılan bu yaklaşım, spesifik etki bileşenlerini gidermek için modeli değişkenlerin birinci farkları çerçevesinde değerlendirmekte ve bağımsız değişkenlerin gecikmeli değerlerini "araç değişken" olarak kullanmaktadır (Soto, 2009: 2).

Arellano ve Bond (1991), bağımlı değişkenin gecikmeli değerleri ile hata terimleri arasında ortoganalite koşullarını sağlarsa, araç değişkenlerin dinamik panel modelinde elde edilebileceğini ileri sürmektedir. Bu durumu daha iyi açıklamak adına açıklayıcı değişken içermeyen basit otoregresif model şu şekildedir:

$$
y_{i t}=\delta y_{i, t-1}+u_{i t} \quad i=1, \ldots, N ; t=1, \ldots, T
$$

Hata teriminin $u_{i t}=\mu_{i}+v_{i t}$ şeklinde oluştuğu ve $\mu_{i} \sim\left(0, \sigma_{\mu}^{2}\right)$ ve $v_{i t} \sim\left(0, \sigma_{v}^{2}\right) \mu_{i}$ ve $v_{i t}$ değişkenlerinin 0 ortalama ve sabit varyansa sahip olduğu ve bu iki değişkenin birbirinden ve kendi aralarında bağımsız olduğu varsayılmaktadır. $N \rightarrow \infty$ ve T sabit iken tutarlı bir tahmin elde etmek için bireysel etkileri elemek için birinci farkı alırız:

$$
y_{i t}-y_{i, t-1}=\delta\left(y_{i, t-1}-y_{i, t-2}\right)+\left(v_{i t}-v_{i, t-1}\right)
$$

4 nolu denklemde farkı alınan $\left(v_{i t}-v_{i, t-1}\right)$ hata teriminin $\mathrm{MA}(1)$ birim kök sürecinde olduğu bilinmektedir. Bu ilişkiyi ilk gözlemleyebildiğimiz durum olan $t=3$ için ise denklem aşağıdaki forma dönüşmektedir:

$$
y_{i 3}-y_{i 2}=\delta\left(y_{i 2}-y_{i 1}\right)+\left(v_{i 3}-v_{i 2}\right)
$$

5 nolu denklemde $y_{i 1}, v_{i t}$ ile olmadığı gibi $\left(v_{i 3}-v_{i 2}\right)$ ile de seri korelasyonlu olmadığı ve $\left(y_{i 2}-y_{i 1}\right)$ ile yüksek korelasyona sahip olduğu için artık geçerli bir araç değişken haline gelmektedir. $t=4$ için ise durum değişmekte ve aşağıdaki hale dönüşmektedir:

$$
y_{i 4}-y_{i 3}=\delta\left(y_{i 3}-y_{i 2}\right)+\left(v_{i 4}-v_{i 3}\right)
$$

6 nolu denklemde $y_{i 1}$ 'in yanısıra $y_{i 2}$ de $\left(y_{i 3}-y_{i 2}\right)$ için geçerli araç değişken haline gelmekte, çünkü hem $y_{i 2}$ hem de $y_{i 1}\left(v_{i 4}-v_{i 3}\right)$ ile seri korelasyonlu değildir. Bu süreç devam ettirildiğinde, $\mathrm{T}$ dönemine kadarki her bir sonraki dönem için ilave geçerli bir araç değişken eklenirse geçerli araç değişkenler $\left(y_{i 1}, y_{i 2}, \ldots, y_{i, T-2}\right)$ olacaktır (Baltagi, 2005:136-137).

Araç değişken süreci devam ettirildiğinde araç değişkenlerin matris yoluyla çözümlerine Holtz-Eakin (1988), Holtz-Eakin, Newey ve Rosen (1988) ve Ahn ve Schmidt (1995) çalışmalarında belirtilen moment koşullarının da eklenmesi ile birlikte Arellano ve Bond (1991) önerdiği tek aşamalı tahminciye $\left(\delta_{1}\right)$ ulaşılmaktadır. Hansen (1982)'in önerdiği uygun GMM tahmincisi $N \rightarrow \infty$ ve T sabit iken durumu ile benzemektedir. Arellano ve Bond (1991) ise tek aşamalı tutarlı tahminciden elde edilen hata teriminin fark 
alınmış hali $(\Delta v)$ ile Hansen (1982)'in önerdiği tutarlı tahmincinin $\left(\delta_{1}\right)$ yer değiştirilmesini önermektedir. Hem Hansen (1982) tahminci $\left(\delta_{1}\right)$ hem de Arellano ve Bond (1991) iki aşamalı tahminci $\left(\delta_{2}\right)$ hata terimleri sıfır ortalama ve sabit varyansa sahip olduğu dikkate alınmalıdır (Baltagi, 2005:137-138).

\subsection{Hipotezler ve Veri}

Çalışmada, geçiş ekonomilerinde doğrudan yabancı yatırımların ekonomik büyüme üzerindeki etkisinin büyüme modelleri çerçevesinde araştırılması amacıyla, söz konusu geçiş ekonomilerine ait 19972016 dönemine ait veriler kullanıımışır. Çalışmanın analizinde kullanılan değişkenlerin adları ve açıklamaları ile elde edildiği kaynaklar Tablo 1'de sunulmaktadır. Tüm değişkenler ile dengeli panel modeli oluşturulmuştur.

Tablo 1. Modelde Kullanılan Değişkenler

\begin{tabular}{|c|c|c|}
\hline Değişken & Açıklama & Kaynak \\
\hline growth & Sabit fiyatlarla büyüme oranı (yıllık, \%) & Dünya Bankası \\
\hline fdi & $\begin{array}{l}\text { Doğrudan yabancı yatırımlar, net } \\
\text { girişlerin GSYiH'ye oranı (yıllık, \%) }\end{array}$ & Dünya Bankası \\
\hline gov & $\begin{array}{l}\text { Toplam kamu harcamalarının GSYiH'ye } \\
\text { oranı (yıllık, \%) }\end{array}$ & Dünya Bankası \\
\hline tra & $\begin{array}{l}\text { Toplam ticaretin GSYIH'ye oranı } \\
\text { (yıllık, \%) }\end{array}$ & Dünya Bankası \\
\hline hdi & İnsani kalkınma endeksi & $\begin{array}{c}\text { Birleşmiş Milletler } \\
\text { Kalkınma Raporu (UNDP) }\end{array}$ \\
\hline
\end{tabular}

growth, fdi, gov, tra değişkenleri Dünya Bankası'nın WDI (World Development Indicators) veritabanından derlenmiştir. Ekonometrik olarak doğru yorumlar elde etmek amacıyla bahsedilen değişkenlerin GSYiH'ye oranı kullanılmıştır. Beşeri sermayeyi temsilen kullanılan insani kalkınma endeksi ( $h d i)$, Birleşmiş Milletler Kalkınma Programı (UNDP, 2018) resmi sitesinden derlenmiştir. Hdi değişkeni endeks değeri olarak kullanıldığı için GSYiH'ye oranlanmamıştır.

Geçiş ekonomilerine giriş yapan doğrudan yabancı yatırımların ilgili ekonomilerin ekonomik büyümeleri üzerinde pozitif etkiler yapması beklenmektedir. Model ayrıca, beşeri sermayenin, işgücünün, ticaret hacmi ve kamu harcamaları gibi değişkenlerin de ekonomik büyüme üzerinde olumlu etkiler yapacağını öngörmektedir.

Kamu harcamaları ve doğrudan yabancı yatırımlar ilişkisi bu iki değiş̧enin sermaye birikimi sağlaması açısından önem arz etmektedir. Ayrıca doğrudan yabancı yatırımlar ülkeye beraberinde önemli bir teknolojik değişim ve istihdam olanakları da getirmekte; işgücünün, eğitim ile birlikte sahip olduğu nitelikler de artmaktadır. Çok uluslu şirketler yatırım yaptıkları ülkeye beceri ve bilgi birikimi ile donatılmış yönetici ve uzman kadrolarıla gelmekte, bu know-how hem yerel şirketlere hem de yabancı ortaklarına aktarılabilmektedir. Tüm bunlar, ev sahibi ekonomideki ekonomik büyümeye olumlu katkıda bulunmaktadır. Bu açıdan doğrudan yabancı yatırımların ekonomik büyüme üzerinde olumlu etkileri olması beklenmektedir.

Kamu harcaması ile ekonomik büyüme arasındaki ilişki, iktisat teorisi çerçevesinde üzerinde farkı kabullerin bulunduğu bir alan konumundadır. Wagner Yasası, ekonomik büyüme süreci ile birlikte kamu harcamalarında bir artış yaşanacağını yani kamu harcamalarındaki artışın bir nedenden ziyade sonuç olduğunu ileri sürmektedir. Keynesyen görüş ise; Wagner Yasası'nın aksine kamu harcamalarında ortaya çıkan artışların ekonomik büyüme yaratacağını savunmaktadır. Nitekim, hükümetlerin yapmış olduğu harcamalar, çarpan etkisi yaratarak büyüme rakamları üzerinde çok daha yüksek etkiler yaratacaktır. 
Ekonomik büyümenin önemli bir bileşeni de beşeri sermayedir. Beşeri sermayedeki artışlar, aynı zamanda ülkedeki fiziksel sermayenin daha yüksek bir miktara ulaşmasına da neden olabilmektedir. Daha iyi eğitim ve sağlık olanaklarıyla donatılmış nitelikli işgücü, nispeten daha niteliksiz işgücü ile kıyaslandığında, belirli bir alanda daha fazla üretim yapabilir. Bu durum beşeri sermaye ile ekonomik büyüme arasındaki pozitif ilişkiyi gösterdiği gibi, aynı zamanda ülkeye giren doğrudan yabancı yatırımların etkilediği daha nitelikli işgücü etkileşimi ile birlikte ekonomik büyümeye diğer bir katkısını da göstermektedir.

Son olarak ülkelerin ticaret hacimlerinin artması, ülke içinde daha yüksek uzmanlaşmaya yol açmakta ve dolayısıyla ülkelerin karşılaştırmalı üstünlük alanlarından yararlanmasına izin vererek, toplam faktör verimliliği ve ekonomik büyümede kazanımlar elde etmelerine neden olmaktadır. Bu noktadan hareketle, modelde hem GSYH'deki ticaret payının hem de doğrudan yabancı yatırım ve ticaret arasındaki etkileşimin ekonomik büyümeyi pozitif etkilemesi beklenmektedir.

Çalışmada kullanılan değişkenlere ait hipotezlerin ardından, değişkenlere ait özet istatistiklere, normallik testlerine ve korelasyon matrisine sırasıyla Tablo 2, Tablo 3 ve Tablo 4'te yer verilmektedir.

Tablo 2. Değişkenlere Ait Özet İstatistikler

\begin{tabular}{|c|c|c|c|c|c|}
\hline Değişken & Gözlem & Ortalama & Std. Sapma & Min. & Mak. \\
\hline growth & 540 & 4.604771 & 5.007929 & -14.81416 & 34.5 \\
\hline fdi & 540 & 5.806374 & 6.958445 & -37.16565 & 55.0759 \\
\hline gov & 540 & 16.3389 & 4.730065 & 3.460336 & 27.39892 \\
\hline tra & 540 & 101.8108 & 32.17798 & 32.84432 & 185.7471 \\
\hline hdi & 540 & 0.7309704 & 0.088811 & 0.396 & 0.892 \\
\hline
\end{tabular}

Tablo 3. Değişkenlere Ait Normallik Testleri

\begin{tabular}{|c|c|c|c|c|c|c|}
\hline \multirow{2}{*}{ Değişken } & \multirow{2}{*}{ Gözlem } & \multirow{2}{*}{$\begin{array}{c}\text { Normallik testi } \\
\text { (Doornik-Hansen) } \\
\end{array}$} & \multicolumn{4}{|c|}{ Normallik testi } \\
\hline & & & Çarpıklık & Basıklık & adj chi2(2) & Prob>chi2 \\
\hline growth & 540 & $\begin{array}{c}\operatorname{chi} 2(2)=321.679 \\
\text { Prob }>\text { chi2 }=0.0000\end{array}$ & 0.0015 & 0.0000 & 71.28 & 0.0000 \\
\hline fdi & 540 & $\begin{array}{c}\operatorname{chi} 2(2)=461.614 \\
\text { Prob }>\text { chi2 }=0.0000\end{array}$ & 0.0000 & 0.0000 & . & 0.0000 \\
\hline gov & 540 & $\begin{array}{c}\operatorname{chi} 2(2)=104.111 \\
\text { Prob }>\text { chi2 }=0.0000\end{array}$ & 0.0000 & 0.4702 & 31.90 & 0.0000 \\
\hline tra & 540 & $\begin{array}{c}\operatorname{chi} 2(2)=19.847 \\
\text { Prob }>\text { chi2 }=0.0000\end{array}$ & 0.0073 & 0.0040 & 13.76 & 0.0010 \\
\hline hdi & 540 & $\begin{array}{c}\operatorname{chi} 2(2)=60.330 \\
\text { Prob }>\text { chi2 }=0.0000\end{array}$ & 0.0000 & 0.0007 & 46.79 & 0.0000 \\
\hline $\begin{array}{c}\text { Tüm } \\
\text { değişkenler }\end{array}$ & & $\begin{array}{l}\operatorname{chi} 2(12)=1.35 \mathrm{e}+05 \\
\operatorname{Prob}>\text { chi } 2=0.0000\end{array}$ & & & & \\
\hline
\end{tabular}

Tablo 4. Değişkenlere Ait Korelasyon Matrisi

\begin{tabular}{|c|c|c|c|c|c|}
\hline Değişken & growth & fdi & gov & tra & hdi \\
\cline { 1 - 2 } growth & 1.0000 & & & \\
\cline { 1 - 2 } fdi & 0.2353 & 1.0000 & & & \\
\cline { 1 - 2 } gov & -0.2952 & -0.1542 & 1.0000 & & \\
\cline { 1 - 2 } tra & -0.0034 & 0.1086 & 0.1118 & 1.0000 & \\
\cline { 1 - 1 } hdi & -0.2848 & -0.0830 & 0.5279 & 0.1728 & 1.0000 \\
\hline
\end{tabular}


Tablo 2'de çalışmada kullanılan tüm değişkenlere ilişkin özet istatistiklere yer verilmektedir. Değişkenlere ait ortalama değerler, standart sapma, minimum ve maksimum değerleri yer almaktadır. Tablo 3'te değişkenlere ait normallik testleri yer almaktadır. Doornik ve Hansen (2008) testi ile değişkenlerin ayrı ayrı normallik değerleri test edilebileceği gibi, değişkenler toplu olarak da test edilebilmektedir. Doornik ve Hansen test sonuçlarına göre değişkenlerin normal dağılıma sahip olduğu $H_{0}$ hipotezi reddedilerek, normal dağılıma uymadığı sonucuna ulaşılmıştır. Ancak tabloya eklenen diğer önemli tanımlayıcı istatistikler olan çarpıklık ve basıkıı ölçüleri de normal dağılımı açıklayabilmektedir. Tüm değişkenlerin çarpıklık ve basıklık değerleri göz önüne alındığında, bu değerlerin 0’a yakın olması, değişkenlerin normal dağılıma uyduğunu belirtmektedir. Seçilen dönem için incelenen değişkenler çarpıklığı 0 'dan ve basıklığı 3'ten sapma gösterdikçe Jargue-Berra test istatistiği büyüme gösterdiği için, sözkonusu verilerin normallik test sonuçlarında sıkıntı görülmemektedir.

Tablo 4'teki değişkenlere ait korelasyon matrisinden elde edilen sonuçlara göre; doğrudan yabancı yatırımlar ve ekonomik büyüme arasında aynı yönlü, diğer değişkenler ve ekonomik büyüme arasında ters yönlü korelasyon görülmektedir. Korelasyon matrisinde dikkat çeken bir durum ise, en güçlü ilişkinin toplam hükümet harcamaları ve beşeri sermaye arasında olması ve bu ilişkinin pozitif çıkmasıdır.

\subsection{Ampirik Sonuçlar}

Tablo 5, sütunlarda sırasıyla modelin farklı panel metotlarıyla tahmin edilen değerlerini göstermektedir. Tablodaki 1. Sütun havuzlanmış EKK tahmin modelini, 2. sütun sabit etkiler modelini, 3. sütun rassal etkiler modelini, 4, 5 ve 6 . Sütunda yer alan modeller ise Arellano Bond tahmincisi kullanılarak elde edilen lineer dinamik panel veri tahmin sonuçlarını göstermektedir.

Tablo 5'teki ilk üç tahmin sonuçları değerlendirildiğinde, tüm değişkenlerin istatistiksel olarak anlamlı ve katsayı işaretlerinin de hipotezlerle uyumlu olduğu görülmektedir. Katsayı işaretlerinin pozitif olması teorik beklenti ve hipotezlerle örtüşmektedir.

Tüm geçiş ekonomileri için elde edilen tahmin sonuçlarına bakıldığında; Arelano-Bond, ArelanoBondmax, Arelano-Bondtwostep yöntemlerinde yine tüm değişkenler anlamlı bulunmuş olup katsayı işareti tüm değişkenler için pozitif değerler almaktadır. Buna göre geçiş ekonomilerinde doğrudan yabancı yatırımların, kamu harcamalarının, ticaret hacminin ve insani kalkınma endeksinin ekonomik büyüme üzerinde pozitif etkileri olduğu görülmektedir. Modelden elde edilen diğer önemli bir sonuç, Arellano-Bond tahmin yöntemlerinin tümünde insani kalkınma endeksinin istatistiksel olarak \%1 anlamlılık seviyesinde işaretinin pozitif ve katsayısının oldukça yüksek (sırasıyla 7.301, 5.249, 8.000) olması, beşeri sermayeyi temsil eden bu değişkenin ekonomik büyümeyi diğer değişkenlere kıyasla daha fazla etkilediği görülmektedir. Bu durum aynı zamanda içsel büyüme modeli çerçevesinde modele eklenen bu değişkenin seçiminin isabetli olduğunu da göstermektedir. İçsel büyüme modeline bağlı kalınarak oluşturulan modelin değişkenlerine ilişkin tahmin sonuçlarının iktisadi beklentilerle uygun olduğu görülmektedir.

Sonuçların ekonometrik altyapısını desteklemek için yapılan Sargan Testi sonuçlarına da analizde yer verilmektedir. Tüm tahminlerde aşırı tanımlama kısıtlamalarının geçerli olduğu, yani araç değişkenlerin de geçerli olduğu söylenebilir.

Tablo 5'teki iki aşamalı Arellano-Bond tahminci sonuçları ile birlikte otokorelasyon test sonuçlarına da yer verilmiştir. Buna göre, bu yöntemle elde edilen sonuçlarda birinci dereceden negatif otokorelasyon (AR1) söz konusu iken, ikinci dereceden otokorelasyon (AR2) ise \%1 anlamllık seviyesinde yoktur. 


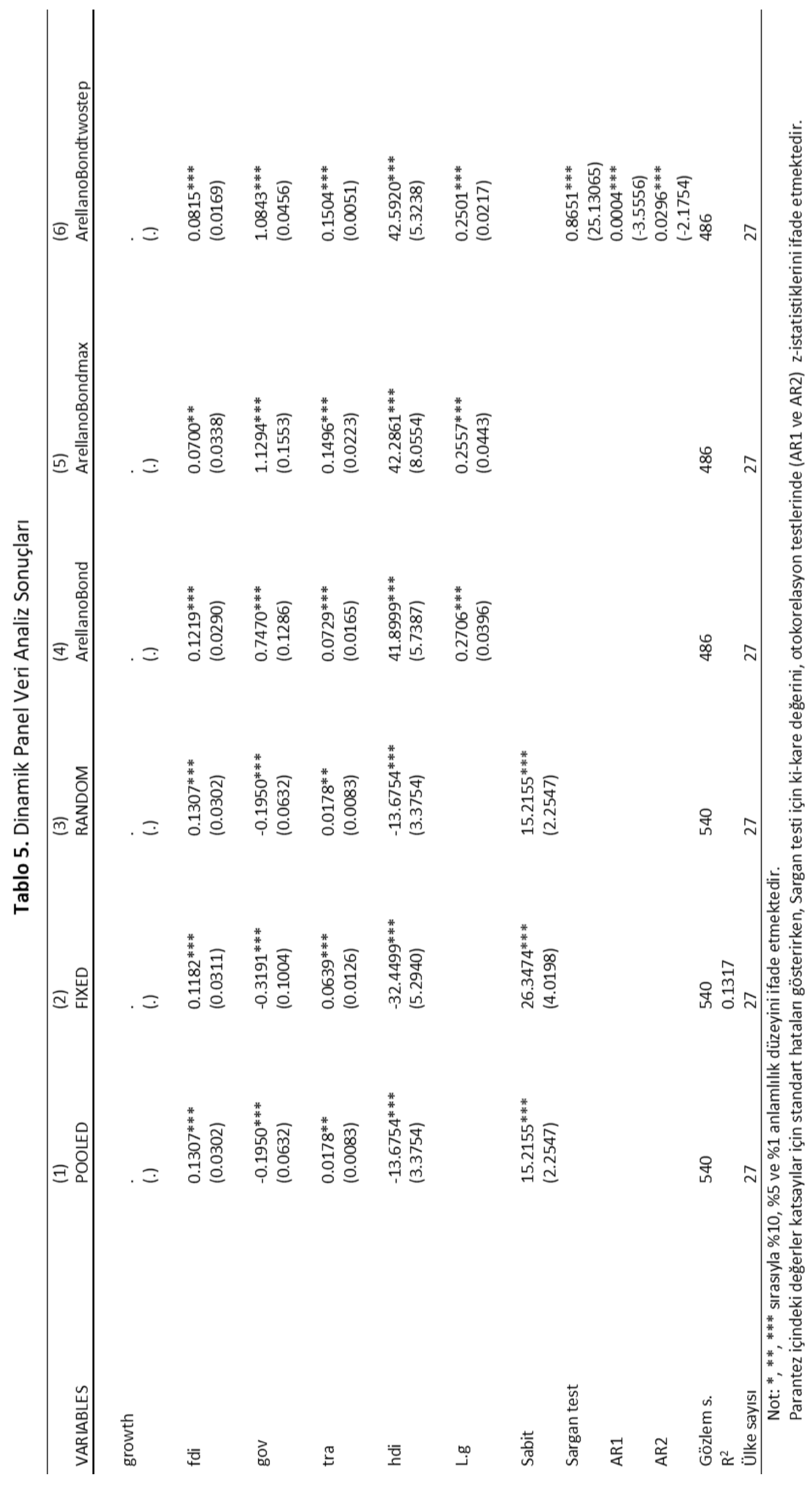




\section{Sonuç}

Çalışmada 1997-2016 yıllarını kapsayan döneminde 27 geçiş ekonomisinde, ekonomik büyümeyi etkilediği düşünülen başta doğrudan yabancı yatırım olmak üzere diğer seçilmiş değişkenlerin etkileri incelenmiştir. Literatürde, doğrudan yabancı yatırımlar ve ekonomik büyüme arasındaki ilişkiyi inceleyen hem teorik hem de ampirik birçok çalışma yer almaktadır. Ampirik çalışmalar dikkate alındığında, hepsinde doğrudan yabancı yatırımlar ve ekonomik büyüme arasındaki pozitif ilişkinin varlığı ispatlanmaktadır. Borensztein ve diğerleri (1998) 69 gelişmekte olan ülke için yaptıkları analizde doğrudan yabancı yatıımların ekonomik büyümeyi beşeri sermaye faktörü ile artırdığı sonucuna ulaşmıştır. Campos ve Kinoshita (2002) kendilerinin de literatür ile aynı şekilde doğrudan yabancı yatırımların ekonomik büyümeyi artırdığını 25 Orta ve Doğu Avrupa ve Eski Sovyetler Birliği ülkeleri için kanıtlamıştır. Lamine ve Yang (2010) çalışmasında doğrudan yabancı yatırımların ekonomik büyüme üzerindeki olumlu etkisini Gine Cumhuriyeti özelinde vurgulamıştır. Apergis ve diğerleri (2008) 1991-2004 dönemi için geçiş ekonomilerinde doğrudan yabancı yatırımların ekonomik büyüme üzerindeki olumlu etkisini kanıtlamıştır. Son çalışmalardan biri olan Mello (2017) ise, gelişmekte olan ülkelerde ekonomik büyümenin doğrudan yabancı yatırımlar ile arttığı sonucuna ulaşmıştır.

Çalışmanın literatüre yapmış olduğu katkı, konunun Neoklasik ve içsel büyümenin teorik modellerine dayanan ampirik analiz modelleri çerçevesinde ekonomik büyümeyi etkilediği düşünülen değişkenlerin modele ilave edildiği bir üretim fonksiyonu çerçevesinde ele alınmasıdır. Modele ekonomik büyümeyi etkileyen diğer faktörler olarak beşeri sermayenin, kamu harcamalarının, ticaret hacmi değişkenlerinin eklendiği bir üretim fonksiyonu tahmin edildiğinde, bahsedilen tüm değişkenlerin ekonomik büyümeyi olumlu yönde etkilediği sonucuna varılmıştır. Kamu harcamaları ve doğrudan yabancı yatırım, sermaye birikimi yoluyla ülkelere finansal kaynak sağlayarak ekonomik büyümeyi bu yolla olumlu etkilemektedir. Bununla birlikte, doğrudan yabancı yatırım girişleri ülkelere gözle görülür oranda teknolojik yenilik ve istihdam olanakları sunmakta, bu iki etki ile işgücünün beceri kazanımı ve nitelikleri de artmaktadır. Modelde açıklayıcı değişken olarak yer alan kamu harcamalarının da ekonomik büyüme üzerinde olumlu etkilerinin olduğu tespit edilmiştir.

Ekonomik büyümeyi etkilediği düşünülen beşeri sermayedeki artışlar, aynı zamanda ülkedeki fiziksel sermaye artışında da önemli rol oynamaktadır. Çünkü daha iyi eğitim ve sağık olanaklarıyla donatılmış nitelikli işgücü, daha niteliksiz işgücü ile kıyaslandığında, belirli bir alanda daha fazla üretim yapabilmektedir. Bu durum beşeri sermaye ile ekonomik büyüme arasındaki pozitif ilişkinin arka planını açıklamaktadır. Son olarak, ticaret hacmi değişkeni de hipotezlerle uyumlu olarak ekonomik büyüme üzerinde pozitif etki yapmaktadır. Çalışmadan çıkan en çarpıcı sonuç, doğrudan yabancı yatırımların ekonomik büyüme üzerindeki etkisinin beşeri sermaye artışı ile desteklendiğinde, daha hızıı bir etki yaratabileceği yönündedir.

\section{Son Notlar}

* Bu çalışma, 27-28 Haziran 2018 tarihleri arasında düzenlenen Uluslararası Uygulamalı Ekonomi ve Sosyal Bilimler Kongresinde (International Conference on Empirical Economics and Social Sciences, ICEESS'18) sunulan bildirinin genişletilmiş halidir.

\section{Kaynaklar}

Ağayev, S. (2010). Doğrudan yabancı sermaye yatırımları ve ekonomik büyüme ilişkisi: Geçiş ekonomileri örneğinde panel eşbütünleşme ve panel nedensellik analizleri. Gazi Üniversitesi IiBF Dergisi, 12(1), 159-184.

Ahn, S., \& Schmidt, P. (1995). Efficient estimation of models for dynamic panel data. Journal of Econometrics, 68(1), 527.

Alagöz, M., Erdoğan, S., \& Topallı, N. (2008). Doğrudan yabancı sermaye yatırımları ve ekonomik büyüme: Türkiye deneyimi. Gaziantep Üniversitesi Sosyal Bilimler Dergisi, 7(1), 79-89. 
Apergis, N., Lyroudi, K., \& Vamvakidis, A. (2008). The relationship between foreign direct Investment and economic growth: Evidence from transition countries. Transition Studies Review, 15, 37-51.

Arellano, M., \& Bond, S. (1991). Some tests of specification for panel data: Monte Carlo evidence and an application to employment equations. The Review of Economic Studies, 58, 277-297.

Athukorala, W. (2003). The impact of foreign direct investment of economic growth: A case study in Sri Lanka. 9th International Conference on Sri Lanka Studies, 28-30 November 2003, Matara, Sri Lanka.

Baltagi, H. B. (2005). Econometric analsis of panel data. John Wiley\&Sons, England.

Bevan, A., \& Estrin, S. (2004). The determinants of foreign direct investment into european transition economies. Journal of Comperative Economics, 32, 775-787.

Borensztein, E., Gregorio, J., \& Lee, J. W. (1998). How does foreign direct investment affect economic growth? Journal of International Economics, 45, 115-135.

Campos, N., \& Kinoshita, Y. (2002). Foreign direct investment as technoogy transferred: Some panel evidence from the transition countries. William Davidson Institute Working Paper, No:438.

Carkovic, M., \& R. Levine. (2002). Does foreign direct investment accelerate economic growth? Department of Finance Working Paper, University of Minnesota, USA.

De Mello, L. R. (1997). Foreign direct investments in developing countries and growth: A selective survey. Journal of Development Studies, 34(1), 1-34.

Durham, J. B. (2004). Absorptive capacity and the effects of foreign direct investment and equity foreign portfolio investment on economic growth. European Economic Review, 48(2), 285-306.

Flexner, N. (2000). Foreign direct investment and economic growth in Bolivia 1990-1998. Central Bank of Bolivia Research Paper.

Ghatak, A., \& Halıcıoğlu, F. (2006). Foreign direct investment and economic growth: Some evidence from across the world. MPRA Paper, No:3565, 1-15.

Hansen, L. P. (1982). Large sample properties of genaralized method of moments estimators. Econometrica, 50(4), 10291054.

Hansen, M. W. (1998). Economic theories of transnational corporations, environment and development. Copenhagen Business School Reviews.

Hansen, H., \& Rand, J. (2004). On the causal links between FDI and growth in developing countries: Institute of Economics. DERG Discussion Papers, 4-30.

Hoang, T., Wiboonchutikula, P., \& Tubtimtong, B. (2010). Does foreign direct investment promote economic growth in Wietnam? ASEAN Economic Bulletin, 27(3), 295-311.

Holtz-Eakin, D., Newey, W., \& Rosen, H. (1988). Estimating vector auto regression with panel data. Econometrica, 56(6), 1371-1395.

Holtz-Eakin, D. (1988). Testing for indivudial effects in autoregressive models. Journal of Econometrics, 39(3), 297-307.

IMF (2000a). Transition economies: An IMF perspective on progress and prospects. https://www.imf.org/external/np/exr/ib/2000/110300.htm\#l (Erişim Tarihi:10.12.2018).

IMF (2000b). World economic outlook: Focus on transition economies: Experience and policy issues.

Jadhav, P. (2012). Determinants of foreign direct investment in BRICS economies: Analysis of economic, institutional and political factor. Procedia-Social and Behavioral Sciences, 37, 5-14.

Katarina, L., Papanastasiou, J., \& Vamvakidis, A. (2004). Foreign direct investment and economic growth in transition economies. South Eastern Europe Journal of Economics, 1, 97-110.

Khawar, M. (2005). Foreign direct investment and economic growth: A cross-country analysis, Global Economy Journal, $5(1), 1-14$.

Kumar, N., \& Naradhan, P. (2002). Foreign direct investment, externalities and economic growth in developing countries. RIS Discussion Papers, No:1, 1-37.

Lamine, K. M., \& Yang, D. (2010). Foreign direct investment effect on economic growth: Evidence from Guinea Republic in West Africa. International Journal of Financial Research, 1(1), 49-54.

Lee, M., \& Tcha, M. (2004). The color of money: The effects of foreign direct investment on economic growth in transition economies. Review of World Economics, 140(2), 211-229. 
Li, X., \& Liu, X. (2005). Foreign direct investment and economic growth: An increasingly endogenous relationship. World Development, No:3, 393-407.

Mankiw, N. G., Romer, D., \& Weil, D. (1992). A contribution to the empirics of economic growth. Quarterly Journal of Economics, 107, 407-37.

Melnyk, L., Kubatko, O., \& Pysarenko, S. (2014). The impact of foreign direct investment on economic growth: Case of post communism transition economies. Problems and Perspectives in Management, 12(1), 17-24.

Nair-Reicherd, U., \& Weinhold, D. (2000). Causality tests for cross-country panels: New look at FDI and economic growth in developing countries. Oxford Bulletin of Economics and Statistics, 63(2), 153-171.

Nath, H. (2009). Trade foreign direct investment and growth: Evidence from transition economies. Comporative Economic Studies, 51, 20-50.

Romer, D. (1990). Endogenous technological change. Journal of Political Economy, 98, 71-102.

Salvatore, D., \& T. Hatcher. (1991). Inward oriented and outward oriented trade strategies. Journal of Development Studies, 27, 7-25.

Sohinger, J. (2005). Growth and convergence in European Transition Economies. Eastern European Economics, 43(2), 73-94.

Soto, M. (2009). System GMM estimation with a small number of individuals. Barcelona Economics Working Paper Series, No:395.

Şişman, M., \& Öztürk, O. (2010). Doğrudan yabancı sermaye yatırımları ve uluslararası vergi rekabeti: Bir literatür araştırması. Marmara Üniversitesi IiBF Dergisi, XXIX(II), 47-75.

Tandırcıoğlu, H., \& Özen, A. (2003). Geçiş ekonomilerinde doğrudan yabancı sermaye yatırımları. Dokuz Eylül Üniversitesi Sosyal Bilimler Enstitüsü Dergisi, 5(4), 105-129.

Tatoğlu, Y. F. (2013). Ileri panel veri ekonometrisi: Stata uygulamalı (2. Baskı). İstanbul. Beta Yayıncılık.

Tian, X., Lin, S., \& Lo, V., (2005). Foreign direct investment and economic performance in transition economies: Evidence from China. Post-Comunist Economies, 16(4), 497-510.

UNCTAD, (1998). World investment report-1998, trends and determinants. United Nations, New York and Cenova.

UNDP (2018). Human development reports. http://hdr.undp.org/en/data (Erişim Tarihi:15 Mayıs 2018).

World Bank (2018). World development indicators. http://databank.worldbank.org/data/source/world-developmentindicators (Erişim Tarihi:15 Mayıs 2018).

Yapraklı, S. (2006). Türkiye'de doğrudan yabancı yatırımların ekonomik belirleyicileri üzerine ekonometrik bir analiz. D.E.i.i.B.F. Dergisi, 21(2), 23-48.

Yavuz, H. (2006). Geçiş ekonomilerinde ekonomik büyüme. Türk Idare Dergisi, Haziran 2006, 89-105.

Zhang, K. H. (2001). Does foreign direct investment promote economic growth? Evidence from East Asia and Latin America. Contemporary Economic Policy, 19(2), 175-185. 
This Page Intentionally Left Blank 